\title{
Object Oriented Image Analysis in Remote Sensing of Forest and Vineyard Areas
}

\author{
Miro GOVEDARICA ${ }^{1}$, Aleksandar RISTIĆ ${ }^{1 *}$, Dušan JOVANOVIĆ ${ }^{1}$, Mihai HERBEI ${ }^{2}$, Florin SALA ${ }^{3}$ \\ ${ }^{1}$ Geospatial Technologies and Systems Centre University of Novi Sad, Faculty of Technical Sciences, Trg \\ Dositeja Obradovića 6, 21000 Novi Sad, \\ ${ }^{2}$ Cartography and GIS, Banat University of Agricultural Sciences and Veterinary Medicine, "Regele \\ Mihai I al României", from Timisoara, Calea Aradului 119, 300645, Timisoara, Romania \\ ${ }^{3}$ Soil Science and Plant Nutrition, Banat University of Agricultural Sciences and Veterinary Medicine \\ "Regele Mihai I al României" from Timisoara, 119, 300645, Timisoara, Romania \\ *)corresponding author, e-mail: aristic@uns.ac.rs
}

BulletinUASVM Horticulture 72(2) / 2015

Print ISSN 1843-5254, Electronic ISSN 1843-5394

DOI:10.15835/buasvmcn-hort:11409

\begin{abstract}
The study of vegetation cover, forests, orchards or vineyards and crops through satellite techniques is increasingly promoted as a result of facilities they offer. Since 2010 until today, it is launched over 50 satellite platforms, delivering images of the Earth's surface with different spectral, spatial and radiometric characteristics. New satellite images such as RapidEye, WorldView2 or WorldView3, with its high spatial and radiometric resolution, prevents the use of the standard image analysis techniques (such as supervised or unsupervised), and involves the use of modern methods in image analysis, such as object base image analysis. A number of methods and techniques for processing and analysis of satellite images are developed to increase the precision of the working, given the diversity of vegetation structure analysis and expected results. This study aimed to analyze the capabilities of object-oriented image analysis (OBIA) for recognition forest and vineyard areas. OBIA is automated process of object extraction by modelling of human visual system for image interpretation. The basis for classification process is object, which is created according to the set of characteristics. In object-oriented approach classification description is based on classification rules including spectral characteristics, size, shape, as well as content and texture information. Analysis is done on multispectral imagery of high and very high spatial resolution. Represented results show the usefulness of RapidEye and WorldView2 images as well as importance of classification based on OBIA. Object-oriented image analysis (OBIA) method based on satellite imagery has facilitated the recognition forest and vineyard areas with high accuracy.
\end{abstract}

Keywords: forest, image analysis, OBIA, remote sensing, vineyard

\section{INTRODUCTION}

The use of remote sensing technology for the needs of geospatial facilities and land cover mapping has become a key factor in applications in various fields, primarily in the field of the environment(Govedarica etal2011,2012), forestry (Jovanović et al 2010), hydrology (Jovanović et al 2007, Luković et al 2008), agriculture (Govedarica et al 2015, Jovanović et al 2011, 2014, 2014), urbanism (Badnjarević et al 2011, Jovanović et al 2014), geology (Badnjarević et al 2012), transport infrastructure, change detection (Jovanović et al 2006, 2011) and other areas (Jovanović et al 2012). Management of natural resources and infrastructure, and planning and monitoring programs depend on accurate information, which can be quickly and adequately obtained using and processing remote sensing data.

The most common techniques of remote sensing data acquisition can be divided into data that are obtained from satellite platforms, then the data obtained from aerial platforms and 
data obtained from ground-based (terrestrial) platform. Common to all these data is a lot of processing steps, in that way to get qualitative and usable information

Methods of processing of these data are primarily related to the classification for different purposes and different applications. Methods of classification of geospatial objects depend first of all on what type of remote sensing data is concerned, and second, on the quality and accuracy assessment of classification. These parameters largely depend on whether it is the data with very high spatial and radiometric resolution (satellite images of high spatial resolution - WorldView2, WorldView3, IKONOS, QuicBird), or if the data are with high or medium resolution (RapidEye SPOT, IRSS, Landsat satellite platforms).

There are a large number of algorithms for classification of geospatial objects, whereby they can be roughly divided into the traditional algorithms, the so-called pixel-based image analysis algorithms, and object based image analysis (OBIA). Traditional algorithms of classification of data obtained by remote sensing are based on the values of pixels. With these algorithms, multispectral data or pixels are used as the basis for numerical categorization or classification. These algorithms are based on the conventional techniques of the statistics of the observed data, i.e.. pixels. Examples of these techniques are a classification with training and classification without training (supervised and unsupervised classification). For classification with training, image analysis is the process of categorizing pixels in different classes, in which every class is numerically describe. In this process we choose a representative set of pixels (the socalled training set) which numerically interpret the desired class or category. Thereafter, each pixel of the observed image numerically compared with each of the training categories and then joins some of them.

In the pixel-based classification methods, pixels are the primary data of image processing. The traditional classification (supervised or unsupervised) is based on a single pixel, and the main objective of the these procedures is to automatically categorize all pixels in the image in to desired class or category. These classification methods are used only color attributes of each pixel, and a lot of these pixel-based classifier algorithms classifies each pixel independently and regardless of adjacent pixels, leading to neglect of spatial autocorrelation of observed pixels. These techniques were indispensable until the appearance of object-based image analysis.

Great improvement have been made with the approach of classification algorithms based on single image objects (object-based, OBIA). This approach combines spectral information that carries each pixel (color) with spatial information, texture and context of each pixel with respect to adjacent pixels. The procedure is primarily based on the process of image segmentation. Segmentation is the process of dividing the image into segments or objects with a certain number of pixels. Each object that is formed in the process of segmentation is characterized by its shape, size, color and topological relationships with neighboring objects.

Matinfar et al (2007) in their study, used Landsat7 ETM + (Enhanced Thematic Mapper) with six spectral bands for the classification of 14 different types of land cover (classes), for the area of central Iran. They have been use pixelbased classification based on minimum distance algorithm and object-oriented classification, based on multiresolution segmentation. The results showed that the object-oriented classification (91\%) gave better results than pixel-based classification $(81 \%)$.

Gao and Mas (2008) uses satellite imagery of different spatial resolution for classification. They have been used SPOT- 5 with a spatial resolution of $10 \mathrm{~m}$, Landsat7 with spatial resolution of 30 $\mathrm{m}$ and MODIS (Moderate Resolution Imaging Spectroradiometer) with a spatial resolution of $100 \mathrm{~m}$ and $250 \mathrm{~m}$. The paper compares the results of two types of classification and gives an overview of the impact on the performance of the classification on imagery with different spatial resolutions. Pixel based classification included four basic algorithm minimum distance, nearest neighbor, parallelepiped classifier and maximum likelihood classifier. Object-based classification is comprised of two steps, multiresolution segmentation, as a first step, and classification on the basis of spectral and spatial characteristics of objects created in the process of segmentation, as a second step. The paper shows that OBIA classification of the two sets of images with four different spatial resolution usually achieves 
greater accuracy than classification based on pixels. Also, this work has shown that an increase in the spatial resolution reduces the difference in accuracy.

The advantage brought by the satellite platform with high spatial resolution, such as, for example, WorldView-2 (WV2) allow us to resolve the problems that existed with the satellite platforms of medium and low spectral and spatial resolution. The lack of detail in the process of recognition of certain geospatial objects and the presence of certain problems in identifying land cover due to the small number of spectral characteristics are eliminated with the arrival of advanced satellite platforms. Images of high spatial and spectral resolution such as WV2 is especially important in urban applications and detailed agriculture and forestry classification applications.

Elsharkawy et al (2012) in the paper "New Combined Pixel / Object-Based Technique For Efficient Urban classification Using Worldview-2 Data" use WV2 satellite platform with all 8 bands for classifying shadows, water, vegetation, buildings, bare soil and asphalt roads. In their study, the authors attempt to improve the pixel base classification results with combination with OBIA. In addition, authors used curvelet transformation which is used to detect the borders of buildings (the algorithm for the detection of edges), and together in combination with OBIA, they have been increase the accuracy of the classification of the buildings for more than $30 \%$. The accuracy of the classification for five classes is acceptable, while accuracy for the class building, compared with pixel-based classification increased from $45.8 \%$ to $85.4 \%$.

\section{MATERIALS AND METHODS}

This paper present a method of OBIA classification of satellite images with high and very high spatial resolution, for the purpose of identifying forest and the vineyards areas. The basis of OBIA classification are objects (groups of pixels), which on one side can be represent with various statistical characteristics, vegetation indices, standard deviations, geometric properties of objects and other significant number of properties that can be used for classification. On the other hand, the various hierarchical levels and relationships between image objects and their properties also affect the dimensionality problem.
A very important step in OBIA classification process is process of segmentation of images.

In this paper we used the Full Lambda Schedule segmentation algorithm, which provides the ability to fine-tune the creation of segments based on shape, size, texture, and spectral value. We propose the process, which contain the formation of rules and classifications based on these rules, which is extremely important for the good classification results.

The area of interest in this analysis is the eastern part of the mountain Fruska gora. Fruska gora occupies the northern part of Srem. It stretches in the length of about 75 kilometres and a width of 12 to 15 kilometres and covers an area of about $255 \mathrm{~km}^{2}$. Fruska gora is declared as national park in 1960, and thus became the first national park in Serbia. It is a low mountain, with the highest peak of $539 \mathrm{~m}$ (Red Cot). The valleys of Fruska gora are covered with meadows, pastures and cornfields, and the slopes are covered with orchards and vineyards. Parts of the mountains that are higher than 300 meters are covered with thick deciduous forest. Fruska gora is the largest concentration of linden trees in Southeast Europe, and next to it appear forests of oak, beech, hornbeam, poplar and willow that can be found as monodominantne forest or a mixed composition. The climate and soil of Fruska gora is suitable for growing grapevines and orchards, because of that, some parts of Fruska gora represent a famous wine region in Serbia.

The data used in this analysis are images from two satellite platforms. The first satellite platform is RapidEye, with five bands imagery and 5 meters spatial resolution, whose spectral characteristics are given in the table below (Tab. 1 RapidEye bands with it's wavelength range and spatial resolution1). Beside the high spatial resolution

Tab. 1 RapidEye bands with it's wavelength range and spatial resolution

\begin{tabular}{ccc}
\hline Band & The wavelength range & $\begin{array}{c}\text { Spatial } \\
\text { resolution }\end{array}$ \\
\hline Blue & $440-510 \mathrm{~nm}$ & \\
\hline Green & $520-590 \mathrm{~nm}$ & \\
\cline { 1 - 2 } Red & $630-685 \mathrm{~nm}$ & $5 \mathrm{~m}$ \\
\cline { 1 - 1 } Red Edge & $690-730 \mathrm{~nm}$ & \\
\hline Near-Infrared & $760-850 \mathrm{~nm}$ & \\
\hline
\end{tabular}


of $5 \mathrm{~m}$, large coverage area and availability of images, RapidEye with its Red Edge band, which is located between the red and near infrared, represent a good choice of the platform for the identification of vineyards. Red Edge band with its spectral characteristics, covers an area of the electromagnetic spectrum where the reflection of vegetation suddenly increases (Baranoski and Rokne, 2005). Image acquisition date is 17. 6. 2013., coordinates are in WGS84 system, UTM Projection, Zone 34 North.

The classification of forest areas, will be in accordance with the rules for creating topographic maps at scale 1: 25000, whereby these regulations are taken as a description of the classification task. One of the main characteristics of this regulations (MGI 2005) has shown that forests in its external form, are starting from the surface of $5625 \mathrm{~m}^{2}$, so that area was chosen for minimum mapping unit for forest area. Under the trees are considered the areas that are covered by various types of trees (except orchards), whose height is 3 meters or more, and coverage (watching the projection of canopy) which is greater than $50 \%$, are classified as forest. For the task of forest classification the WorldView-2 platform is chosen, whose main characteristics are given in the table below (Tab. 2 WorldView-2 bands with it's wavelength range and spatial resolution2) and which in addition to the RapidEye satellite platform, is the only satellite platform with the Red Edge band.

The classification of forest areas is performed on the suburban areas of the city Novi Sad, acquisition date of the image is 10.06.2010. Area of interest is located on the south area of the village Bukovac, with the image surface of about $50 \mathrm{~km}^{2}$, the coordinates are in WGS84 system, UTM Projection, Zone 34 North. The figure below (Fig. 1. WorldView-2 image overlap with Open Street Map, displayed with natural and false RGB combination1) shows the area of interest and the entire image in a natural and different false colour combination.

All pre-processing steps, such as pan sharpening of WV-2 images, orthorectification and georeferencing of both satellite images, were performed using ERDAS Imagine 2015 software package. Also, segmentation and OBIA classification of forest and vineyard areas, was performed with the ERDAS Imagine Objective software.

Tab. 2 WorldView-2 bands with it's wavelength range and spatial resolution

\begin{tabular}{ccc}
\hline Band & The wavelength range & $\begin{array}{c}\text { Spatial } \\
\text { resolution }\end{array}$ \\
\hline Panchromatic & $450-800 \mathrm{~nm}$ & $0.5 \mathrm{~m}$ \\
\hline Coastal & $400-450 \mathrm{~nm}$ & \\
\hline Blue & $450-510 \mathrm{~nm}$ & \\
\hline Green & $510-580 \mathrm{~nm}$ & \\
\hline Yellow & $585-625 \mathrm{~nm}$ & \multirow{2}{*}{$2 \mathrm{~m}$} \\
\hline Red & $630-690 \mathrm{~nm}$ & \\
\hline Red Edge & $705-745 \mathrm{~nm}$ & \\
\hline NIR1 & $770-895 \mathrm{~nm}$ & \\
\hline NIR2 & $860-1040 \mathrm{~nm}$ & \\
\hline
\end{tabular}

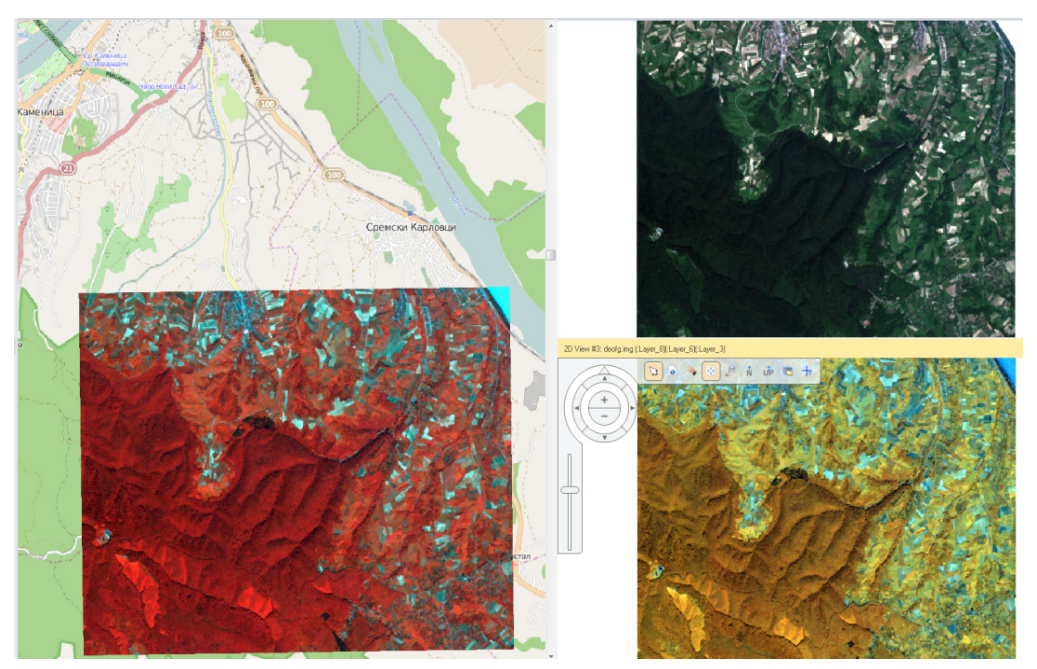

Fig. 1. WorldView-2 image overlap with Open Street Map, displayed with natural and false RGB combination 


\section{RESULTS AND DISCUSSION}

Process of classification of forest areas is basically based on the Full Lambda Schedule (FLS) segmentation algorithm, which is available as part of Objective Erdas Imagine software. The first step in an object-oriented classification is processing the pixel with Single Feature Probability (SFP) function. This function determines the classification of pixels on the basis of training sets that represent a particular class, in our case, a class of forest area. SFP algorithm is used to recognize the pixels with similar characteristics. SFP calculate the probability of each pixel on the basis of training samples. Pixels with values similar to those that represent the forest class, will have a higher probability value. Lower probability value is assigned to pixels that differ significantly from the pixels that represent a forest class. Pixels that have similar values to pixels that represent forest area, are brighter, as compared to the pixels that differ significantly from the pixels that represent this class (Fig. 2. Basic steps in classification process. 2 a).

After that, the resulting probability pixels layer is transformed into a raster object on the basis of the FLS segmentation algorithm. The parameters of this algorithm, which is necessary to adjust, the average size of the segment, the minimum and maximum segment size in pixels, relative spectral weight, relative weight of the texture, the relative weight of the size and relative weight forms, are shown in the table below (Tab. 3. The parameters used in the classification process3), and the results of this step is shown (Fig. 2. Basic steps in classification process. $2 \mathrm{~b}$ ). The parameter that significantly affects the shape and surface of segments is "pixel segment ratio". In this case, this parameter is set to 1000. A lower value would cause a different form of segments, but the surface remained unchanged, while higher values would cause larger segments, which in the case of roads in the area of Fruska gora, which are partly covered with forests, will lead to misclassification.

The best result for relative spectral weight is with a value of 0.80 . Smaller values is increase the surface of the forest area against to the other agriculture crops. The relative weight of the texture is measured as the standard deviation of pixel values (DN - Digital Number) in the segment. In this case, a parameter that relates to the relative weight of the texture is set to 0.70 . The relative weight of the size and relative weight of the shapes are in this case set to 0.50 . Since the task is the classification of forest areas, the segments that represent forest are homogeneous in terms of size and shape, and therefore the optimal weight for size and shape are selected.

After the image segmentation, it is necessary to improve the obtained result by using the corresponding filter. For this purpose, dilate filters, probability and segment merge filters were used. The first parameter (dilate) was used to expand the image objects by adding pixels at the edges of objects. The other parameter which was used in order to improve the results of the segmentation is probability filter. When this filter is set with a minimum value of probability, objects with high probability value of the given minimum values are removed. In this case, the probability value is set to 0.80 . Finally, in order to connect adjacent raster objects from a set of raster objects with a high

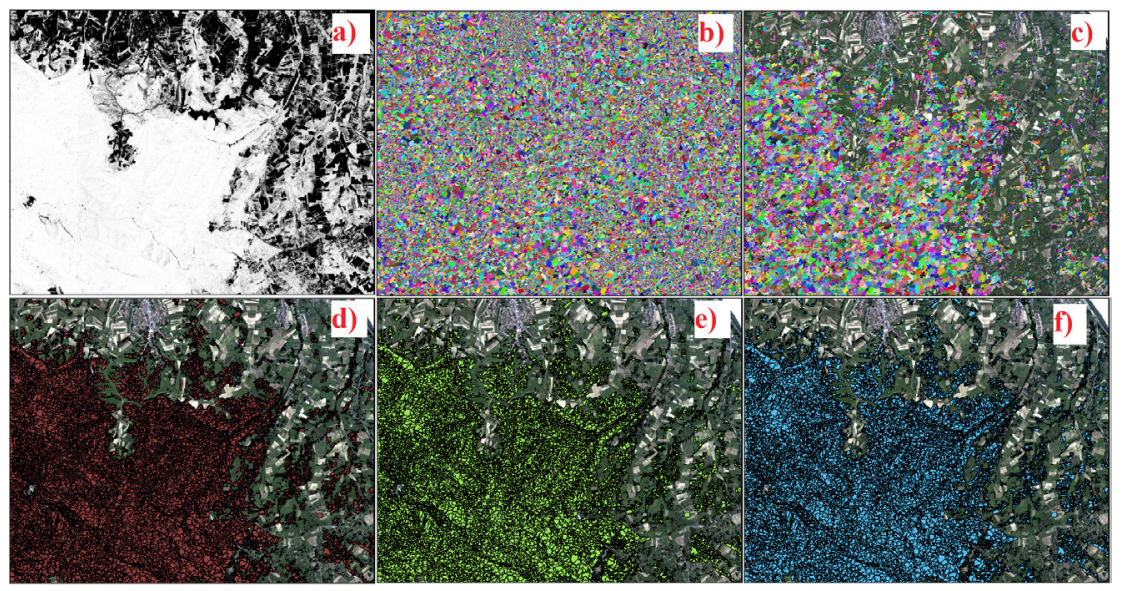

Fig. 2. Basic steps in classification process. 
probability, segment merge algorithm was used. The result of these steps is shown in the figure (Fig. 2. Basic steps in classification process.2 c).

The meaning of object-oriented image analysis is not only to process raster objects, but also to process vector objects. Therefore the conversion of the resulting raster to vector format is obtained, which is also shown in the figure (Fig. 2. Basic steps in classification process. $2 \mathrm{~d}$ ). The resulting vector is enhanced by appropriate algorithms, generalize and iceland filter. The generalization filter is used to remove excess folds and curves in order to object boundaries could be clearer. Iceland filter is used in order to eliminate isolated islands or holes in objects, that occur because of errors in pixels or in homogeneity of the grounds or raster objects. Subsequently, processing of vector objects, in terms of one or more metric indicators that measure the properties of the vector objects, is performed. These object classifiers are used for allocation of a probability to each object from a group of vector objects. Also, for the purposes of classification of forest areas on the satellite image, object indicator that refers to an Area, was used. (Fig. 2. Basic steps in classification process.2 e).

The final step in the object-oriented classification is the last correction of vector objects. Two more algorithms have been used, probability filter and dissolve. Minimum probability is set to 0.80 value. Another operator (Dissolve) is used to remove the borders between adjacent objects that belong to the class that represents the forest. Raster algorithm transforms objects into temporary raster, removes the boundaries between the classes of the same type and make the new border. This parameter determines the resolution in units of maps that are used for temporary raster. The best result is achieved when the pixel size is the same as the original input raster (in this case the pixel size is 0.5 meters). The result of the whole process of classification of forest area is shown with dark green color (Fig. 2 . Basic steps in classification process. $2 \mathrm{f}$ ).

For the purposes of identification vineyards area on RapidEye satellite image, the same algorithms as in classification forest areas process, with certain modifications, were used. After creating the training sets for vineyards area, process of OBIA classification was the same. Hereinafter will be mentioned only the differences between this two classification processes.

Creating raster objects is performed using FLS algorithm. The values relating to spectral components and the texture are set to 0.80 while the parameters relating to the shape and size set to 0.60 . Minimum segment size is 30 and the

Tab. 3. The parameters used in the classification process

\begin{tabular}{|c|c|c|c|}
\hline \multicolumn{2}{|r|}{ Forest classification } & \multicolumn{2}{|c|}{ Vineyards classification } \\
\hline segmentation & pixel segment ratio : 1000 & segmentation & pixel segment ratio : 1000 \\
\hline & spectral : 0.80 & & spectral : 0.80 \\
\hline & texture: 0.70 & & texture: 0.70 \\
\hline & size: 0.50 & & size: 0.50 \\
\hline & shape : 0.50 & & shape : 0.50 \\
\hline dilate & kernel size : 3 & dilate & kernel size : 3 \\
\hline segment merge & number of recursions : 1 & segment merge & number of recursions : 1 \\
\hline & pixel probability weight : 0.50 & & pixel probability weight : 0.50 \\
\hline & probability threshold : 0.10 & & probability threshold : 0.10 \\
\hline & pixel prob. start threshold : 0.90 & & pixel prob. start threshold : 0.90 \\
\hline probability filter & minimum probability : 0.80 & probability filter & minimum probability : 0.80 \\
\hline generalize & tolerance $0.50 \mathrm{~m}$ & generalize & tolerance $0.50 \mathrm{~m}$ \\
\hline island filter & maximum object size 50000 sqm & island filter & maximum object size $50000 \mathrm{sqm}$ \\
\hline geometry & area : pixel probability weight 0.50 & geometry & area : pixel probability weight 0.50 \\
\hline & distribution type : Gaussian & & distribution type : Gaussian \\
\hline probability filter & minimum probability : 0.80 & probability filter & minimum probability : 0.80 \\
\hline dissolve & $0.5 \mathrm{~m}$ & dissolve & $0.5 \mathrm{~m}$ \\
\hline
\end{tabular}




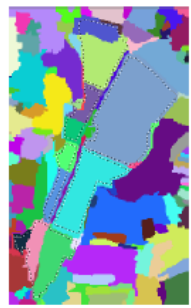

a) $\mathrm{PSR}=500$

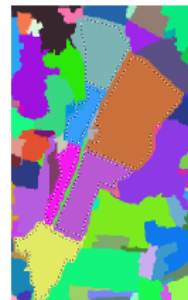

b) $\mathrm{PSR}=800$

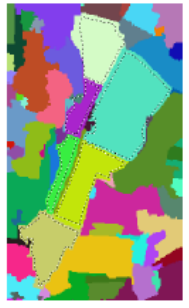

c) $\operatorname{PSR}=1000$
Fig. 3. The average values of segments size

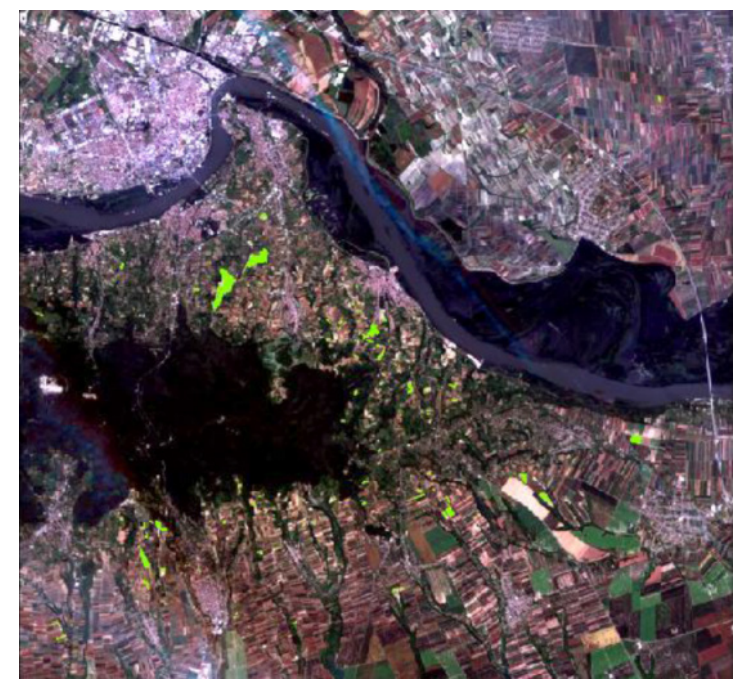

Fig. 4. The resulting vector layer that represents the vineyards (green) loaded via Rapid Eye image

maximum 100000 pixels. In this case, the average size of the segment is set to 800 . The figure (Fig. 3 . The average values of segments size3) shows the difference in segmentation when the average size of the segment ("pixel segment ratio" - PSR) is set at 500, 800 and 1000 pixels.

The figure (Fig. 3. The average values of segments size3) shows that the average segment size with PSR value 800 gave the best results in terms of size and shape segments, especially having in mind that the spatial resolution of image is 5 meters. Probability filter value is set to 0.40 . Such a low threshold probability is set because, a higher value of 0.40 influenced the omission of certain objects, while values less than the set, caused the creation of objects in areas that are not under vineyards. In table (Tab. 3. The parameters used in the classification process3) are shown all parameters values for vineyards classification process. In figure (Fig. 4. The resulting vector layer that represents the vineyards (green) loaded via
Rapid Eye image4) are shown the results of the vineyards classification.

Accuracy assessment is necessary in the classification process. Accuracy assessment determines the quality of the maps obtained using remote sensing data (Congalton and Green 2008). A thematic map derived with a classification may be considered accurate if it provides an unbiased representation of the land cover of the region it portrays. Many methods of accuracy assessment have been discussed in the remote sensing literature. The most widely promoted and used, however, may be derived from a confusion or error matrix. (Foody 2002). The errors matrix or confusion matrix, comparing information between the reference data and classification data for a given sample.

During accuracy assessment it is important to be impartial toward selecting the area that will be chosen as a reference sample. The best way is to take reference samples from the field (RapidEye), but in the case when image is historical, and image has high spatial resolution (like in our case for WV-2 image) it is also possible to collect reference samples by visual analysis. Also, it is advisable that one analyst performed classification and the other accuracy assessment. Thus the impartiality of accuracy assessment will be provided.

The method of accuracy assessment consists of several steps that will be now briefly explained. First step is to choose a sufficient number of reference points for accuracy assessments. In both cases, forest classification and vineyard classification, the estimation of accuracy has been taken over 256 points, uniformly randomly distributed throughout the satellite image. After that, it is necessary for each class check and confirm whether a particular pixel belongs or does not belong to the reference class. This check is executed for each of the 256 points and in the end it creates a report of total accuracy. The resulting accuracy of the classification of forest areas is $96.48 \%$ and for vineyard areas is $83.20 \%$.

\section{DISCUSION}

The main objective of each classification is the extraction of information from data sets that are classified. If we look at satellite images, the main goal of classification is to obtain information about the Earth, or where and what it is on the ground. The results of classification is usually divided into 


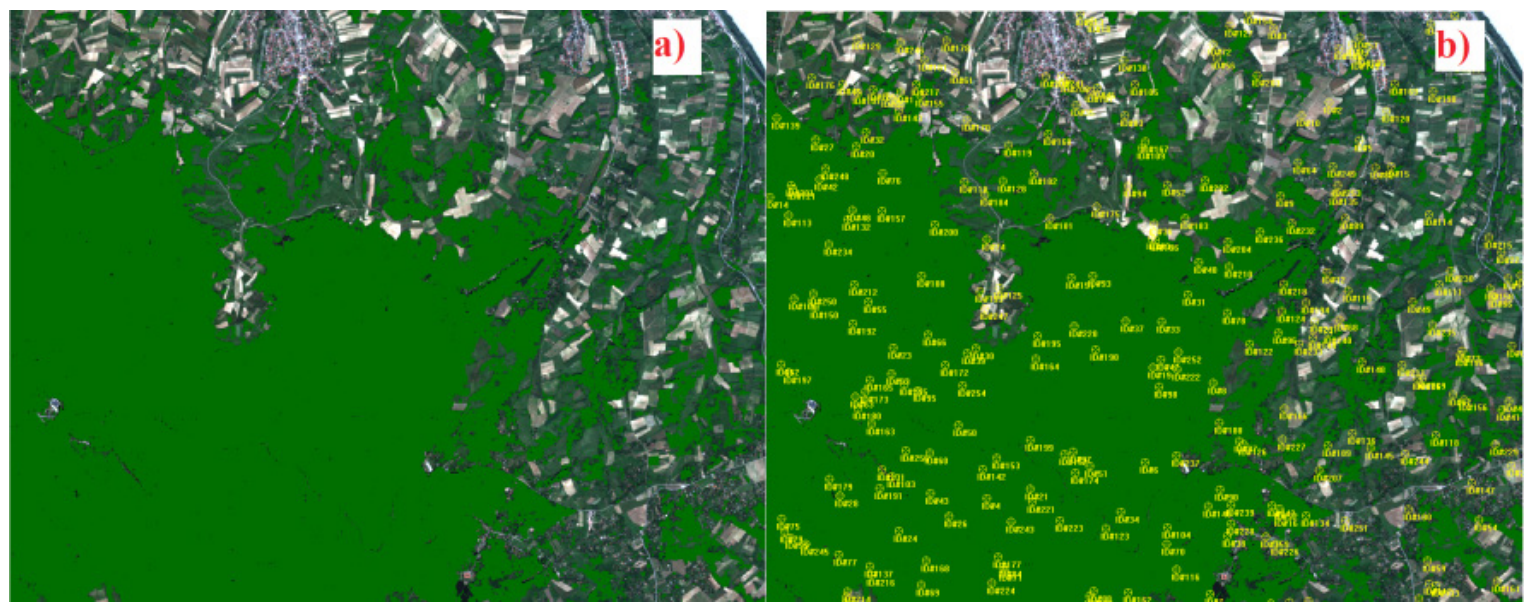

Fig. 5. a) WV2 image overlapped by the result of forest classification, b) control points for accuracy assessment

thematic and quantitative data. Thematic data are usually maps with categorized variables, or maps with thematic classes, such as road maps, facilities maps, land cover maps or maps of the fire areas, maps of flooded areas, various agricultural maps, forest maps, while quantitative data, in fact, represent a maps with continuous variables, such as maps with vegetation indices, biomass maps or maps of trees volume.

The traditional classification method for mapping land cover is based only on the pixel value, where the result is map with categorized classes, where each category, in fact, represent any of the predefined land cover. Common to all methods of classification is basically an attempt to transfer our knowledge to computer and help in the interpretation of images. In this regard, especially when we move away from the spectral characteristics of the image, pixel-based classification (treatment of individual pixels) is limited. What is needed is a connection between human perception and interpretation of the image and the computer classification techniques. From the set of advanced classification techniques, we have used classification based on object-oriented image analysis. Basically, this advanced image classification method is the attempt to interpret the ways that human beings perceive information from the images.

With this study we have implemented an OBIA approach for detection of vineyards in RapidEye images and approach for detection of forest areas in WorldView-2 images. The approach took into consideration the different categories of their spatial, spectral, texture and shape characteristics.
The transferability of the classification rules defined for vineyard area to the forest area, show that the accuracy of identification of certain types of land cover increases with increasing spatial and spectral resolution. OBIA classification of vineyards and forest areas, presented in this paper, represent a good example of classification of satellite images of high and very high resolution.

\section{CONCLUSION}

Process of OBIA classification on satellite images with high and very high spatial resolution obtained vectors that represent forest and vineyards areas. Both images are collected in June, during the lush vegetation of the forest and vineyard area. This information was useful in the classification. Better result were obtained in the classification of forest areas on the WV-2 satellite image. On the other side, vineyards on the RapidEye satellite image are not classified with high accuracy. The reason is that in many winegrowing regions, such as the Fruska gora, the minimum distance between two rows of vines can be up to $1 \mathrm{~m}$. Accordingly, the spatial resolution (which is 5 meters in our case of RapidEye image), image should be lower than $1 \mathrm{~m}$ in order to correctly identify vineyards.

Also, the inhomogeneity of land under vines was a major problem. Different materials in soil had an impact of appearing more classes, not just vineyard class. In addition to inhomogeneity, lush vegetation also had a major impact on the accuracy of classification of vineyards. Land of vineyards is best classified over the area where very early varieties of ripen grapes (from the 5 th 
to the 25th of July). On the other hand, vineyards that have ripen later, due to the inhomogeneity of land and poor vegetation, could not be accurately identified.

The object-based approach provides a good results in process of forestry and vineyard classification on high spatial resolution remotely sensed imagery. The results reveal the potential limitations in object-based classification, when we use images with no appropriate date of acquisition and spatial resolution.

\section{REFERENCES}

1. Badnjarević I, Govedarica M, Jovanović D (2011). The Application of Remote Sensing Technology in Spatial Planning - A Case Study "Spatial Plan of The Protected Property, Special Nature Reserve Upper Danube". I Srpski Geodetski Kongres Beograd.

2. Badnjarević I, Govedarica M, Jovanović D, Pajić V, Ristić A (2012). Geoinformation technologies in the process of terrain slope detection in the area of Fruska gora with reference to potential development of slope processes. Glasnik Srpskog Geografskog Društva 92(4): 51-62.

3. Baranoski G, Rokne J (2005). A practical approach for estimating the red edge position of plant leaf reflectance. International J of Remote Sensing 26: 503-521.

4. Congalton R, Green K (2008). Assessing the accuracy of remotely sensed data: principles and practices. Second Edition CRC Press.

5. Elsharkawy A, Elhabiby M , El-Sheimy N (2012) New Combined Pixel/Object-Based Technique For Efficient Urban Classification Using Worldview-2 Data. International Archives of the Photogrammetry, Remote Sensing and Spatial Information Sciences, Volume XXXIX-B7.

6. Foody G (2002). Status of land cover classification accuracy assessment. Remote Sensing of Environment 80: 185-201.

7. Gao Y, Mas J (2008). A comparison of the performance of pixel-based and object-based classifications over images with various spatial resolutions. GEOBIA 2008 - Pixels, Objects, Intelligence, GEOgraphic Object Based Image Analysis for the 21st Century, ISPRS Conference, Calgary, Canada.

8. Govedarica M, Badnjarević I, Jovanović D, Petrovački D (2011). The analysis of remote sensing technology and the application of satellite imagery of WorldView-2 satellite platform: detection, identification and assessment of vegetation quality in the area of the special nature reserve upper Danube. Architecture and urban planning, civil engineering, geodesy - past, present, future 1(1): 767778.

9. Govedarica M, Petrovački D, Sladić D, Radulović A, Jovanović D, Pajić V, Vrtunski M , Ristić A (2012).
Environmental data in Serbian spatial data infrastructure - Geoportal of ecology. J of Environmental Protection and Ecology 13(3A) : 1990-1997.

10. Govedarica M, Jovanović D, Sabo F (2015). Corn yield estimation in Serbia using Modis 13Q1 product. Remote Sensing and Geo-Information, Paphos.

11. Jovanović D, Govedarica M, Pajić V, Sladić D, Popov S (2006). Monitoring land-use change area of Vojvodina, Serbia using Landsat ETM+ and TM data. Intergeo East Conference, Belgrade.

12. Jovanović D, Govedarica M, Pržulj Đ (2007). Praćenje promena vodenih površina za područje Vojvodine korišćenjem Landsat ETM+ i TM satelitskih snimaka. Vodoprivreda 39(229-230): 337-340.

13. Jovanović D, Govedarica M, Badnjarević I, Pajić V (2010). Object based image analysis in forestry change detection. IEEE International Symposium On Intelligent Systems And Informatics (SISY), Subotica.

14. Jovanović D, Šoškić S, Govedarica M , Badnjarević I (2011). Mapping agricultural crops using remote sensing techniques. Application of GIS technology in protection and usage of agricultural land 1(1): 102-106.

15. Jovanović D, Govedarica M , Badnjarević I (2011). Presenting and comparing the object based image analysis and standard image analysis for change detection of forest areas, using low-resolution satellite imagery. SGEM 2(11): 329-336.

16. Jovanović D, Govedarica M, Sladić D, Radulović A (2012). Geoportal of The Republic of Srpska. METTEG12 1:23-33.

17. Jovanović D, Govedarica M , Rašić D (2014). Remote sensing as a trend in agriculture. Research J of Agricultural Science 46(3): 32-37.

18. Jovanović D, Sabo F, Govedarica M, Marinković B (2014). Crop yield estimation in 2014 for Vojvodina using methods of remote sensing. Field and Vegetable Crops Research 51(3): 145-153.

19. Jovanović D, Govedarica M, Sabo F, Sladić D, Ristić A (2014). Spatial analysis of high-resolution urban thermal patterns in Vojvodina, Serbia. Geocarto International, 30(3-4): 483-505.

20. Luković I, Pajić V, Popov S , Jovanović D (2008). A classification of surface water bodies according to WFS by remote sensing methods. International Conference Planning and Management of Water Resources Systems, Novi Sad.

21. Matinfar H, Sarmadian F, Panah SA, Heck R (2007). Comparisons of Object-Oriented and Pixel-Based Classification of Land Use/Land Cover Types Based on Lansadsat7, Etm + Spectral Bands (Case Study: Arid Region of Iran). American-Eurasian J. Agric. \& Environ. Sci 2(4): 448-456.

22. Military Geographical Institute (2005). Instructions for making digital topographic map, scale 1:25 000, Belgrade. 